\title{
Hygroscopic properties of water-soluble matter and humic-like organics in atmospheric fine aerosol
}

\author{
M. Gysel ${ }^{1}$, E. Weingartner ${ }^{1}$, S. Nyeki ${ }^{1}$, D. Paulsen ${ }^{1}$, U. Baltensperger ${ }^{1}$, I. Galambos ${ }^{2}$, and G. Kiss ${ }^{3}$ \\ ${ }^{1}$ Laboratory of Atmospheric Chemistry, Paul Scherrer Institut, CH-5232 Villigen, Switzerland \\ ${ }^{2}$ Department of Earth and Environmental Sciences, University of Veszprém, 8201 Veszprém, Hungary \\ ${ }^{3}$ Air Chemistry Group of the Hungarian Academy of Sciences, University of Veszprém, 8201 Veszprém, Hungary
}

Received: 27 July 2003 - Published in Atmos. Chem. Phys. Discuss.: 1 October 2003

Revised: 15 December 2003 - Accepted: 28 December 2003 - Published: 22 January 2004

\begin{abstract}
Ambient continental-rural fine aerosol (K-puszta, Hungary, $\mathrm{PM}_{1.5}$ ) was sampled on quartz fibre filters in winter and summer 2001. Water-soluble matter (WSM) was extracted in MilliQ-water, and, in a second step, solid phase extraction was used to isolate the less hydrophilic fraction (ISOM) of the water-soluble organic matter (WSOM) from remaining inorganic salts and "most" hydrophilic organic matter (MHOM). This approach allowed ISOM, which constitutes the major fraction of WSOM, to be isolated from ambient aerosols and investigated in pure form. Hygroscopic properties of both WSM and ISOM extracts as well as of aquatic reference fulvic and humic acids were investigated using a Hygroscopicity Tandem Differential Mobility Analyser (H-TDMA). ISOM deliquesced between $30 \%$ and $60 \%$ relative humidity $(\mathrm{RH})$, and hygroscopic growth factors at $90 \% \mathrm{RH}$ ranged from 1.08 to 1.17 . The hygroscopicity of ISOM is comparable to secondary organic aerosols obtained in smog chamber experiments, but lower than the hygroscopicity of highly soluble organic acids. The hygroscopic behaviour of investigated fulvic and humic acids had similarities to ISOM, but hygroscopic growth factors were slightly smaller and deliquescence was observed at higher RH (75$85 \%$ and $85-95 \%$ RH for fulvic acid and humic acid, respectively). These differences probably originate from larger average molecular mass and lower solubility of fulvic and humic acids.
\end{abstract}

Inorganic composition data, measured ISOM hygroscopicity, and a presumed value for the hygroscopicity of the small remaining MHOM fraction were used to predict hygroscopic growth of WSM extracts. Good agreement between model prediction and measured water uptake was observed with differences (by volume) ranging from $+1 \%$ to $-18 \%$. While deliquescence properties of WSM extracts were mainly determined by the inorganic salts $(42-53 \mathrm{wt} \%$

Correspondence to: E. Weingartner

(ernest.weingartner@psi.ch) of WSM), the WSOM accounted for a significant fraction of particulate water. At $90 \% \mathrm{RH}$, according to model predictions and measurements, about $80-62 \%$ of particulate water in the samples are associated with inorganic salts and about 20-38\% with WSOM. The relative contributions of both distinguished WSOM fractions, ISOM and MHOM, remains uncertain since MHOM was not available in isolated form, but the results suggest that the less abundant MHOM is also important due to its presumably larger hygroscopicity.

\section{Introduction}

Hygroscopic growth of atmospheric aerosol particles plays an important role in numerous atmospheric processes such as climate forcing, visibility degradation, cloud formation and heterogeneous chemistry. In recent years the influence of inorganic salts on these effects has been mainly investigated. Only several inorganic salts constitute the major part of the inorganic aerosol fraction (Heintzenberg, 1989), which is relatively well-characterised regarding its hygroscopic properties (Clegg et al., 1998; Ansari and Pandis, 1999). However, recent experimental and modelling studies strongly indicate that water-soluble organic matter (WSOM) contained in atmospheric aerosol particles is also important. It was also suggested, based on the partitioning of WSOM and waterinsoluble organic matter (WINSOM) between fog droplets and interstitial aerosol particles, that WSOM plays an important role in the droplet nucleation process (Facchini et al., 1999). Furthermore organic species are potential candidates to delay or inhibit efflorescence (Choi and Chan, 2002a) of atmospheric aerosols.

WSOM, in contrast to the inorganic aerosol fraction, is composed of hundreds (or even thousands) of individual species (Saxena and Hildemann, 1996), where each contributes only a small mass fraction towards WSOM. Different approaches are generally used to determine the influence 


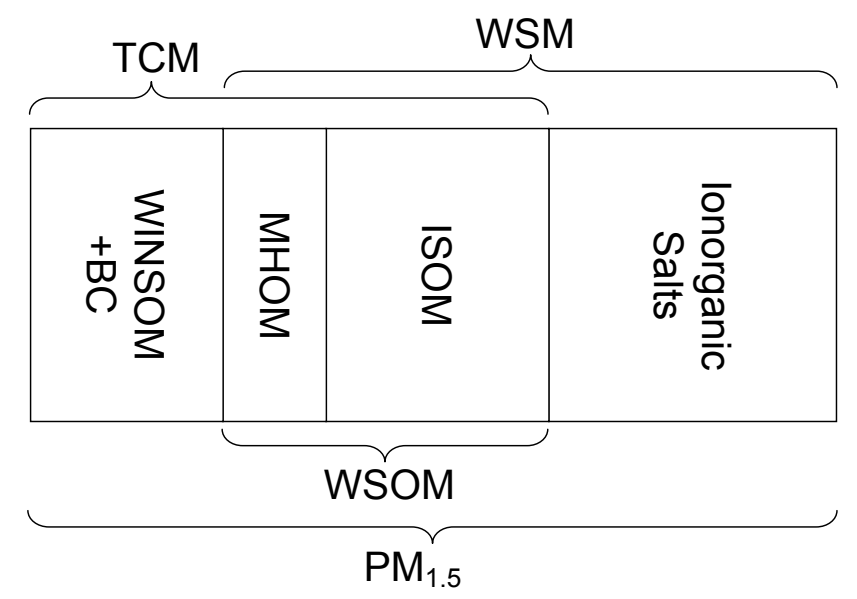

Fig. 1. Compound classification and average chemical composition of total particulate matter with diameter $D \leq 1.5 \mu \mathrm{m}\left(\mathrm{PM}_{1.5}\right)$ : i) Water-insoluble organic matter (WINSOM) and black carbon (BC), ii) most hydrophilic organic matter (MHOM), iii) isolated organic matter (ISOM), iv) inorganic salts, v) water-soluble matter (WSM), vi) water-soluble organic matter (WSOM), and vii) total carbonaceous matter (TCM). The box widths are proportional to the corresponding average mass fractions of all samples (see Table 1).

of WSOM on the hygroscopic behaviour under subsaturated relative humidity (RH) conditions of ambient aerosols. Previous laboratory studies, investigating the hygroscopic properties of organic model substances, have mostly focused on pure and mixed low molecular weight organic acids such as carboxylic acids, dicarboxylic acids, and multifunctional organic acids or their salts (Na et al., 1995; Peng et al., 2001; Peng and Chan, 2001; Prenni et al., 2001; Choi and Chan, 2002b), and on their mixtures with inorganic salts (Cruz and Pandis, 2000; Lightstone et al., 2000; Choi and Chan, 2002a; Choi and Chan, 2002b; Hämeri et al., 2002). First theoretical models for the prediction of the hygroscopic growth of mixed inorganic/organic aerosols were recently introduced by several investigators (Clegg et al., 2001; Ming and Russell, 2001; Ming and Russell, 2002). The hygroscopic properties of artificial secondary organic aerosol obtained by oxidation of typical volatile organic precursors in smog chambers have also been investigated (Virkkula et al., 1999; Cocker III et al., 2001a; Cocker III et al., 2001b; Saathoff et al., 2003). Apart from the hygroscopic properties of organics under subsaturated conditions, their cloud condensation nuclei activity under supersaturated conditions has also been investigated in recent studies (Cruz and Pandis, 1997; Cruz and Pandis, 1998; Corrigan and Novakov, 1999; Prenni et al., 2001; Giebl et al., 2002).

It is more difficult to determine the influence of WSOM in real ambient particles. Towards this aim, hygroscopicity measurements are generally combined with chemical analysis of the inorganic and organic aerosol fractions. Excess water, which cannot be explained by the water uptake of the inorganic aerosol fraction, is then attributed to the organic aerosol fraction. Depending on the sampling location, considerable amounts of excess water have been reported in field studies by (Saxena et al., 1995; Swietlicki et al., 1999; Dick et al., 2000; Speer et al., 2003) when using this method.

The solid phase extraction method, recently developed and characterised by Varga et al. (2001), allows a major fraction of WSOM (so-called isolated organic matter, ISOM, mainly less hydrophilic compounds) to be isolated from total watersoluble matter (WSM). Several studies on ISOM from atmospheric aerosols at the high alpine site Jungfraujoch, Switzerland (Krivácsy et al., 2001) and at the continental-rural site K-puszta, Hungary (Varga et al., 2001; Kiss et al., 2002; Galambos et al., 2004) showed that WSOM consists of up to $70 \mathrm{wt} \%$ ISOM, and that ISOM is mainly composed of humic-like substances. The remaining smaller fraction of WSOM, which cannot be isolated from inorganic salts so far, consists of the "most" hydrophilic organic matter (MHOM). Figure 1 illustrates the classification scheme defined according to the chemical characterisation applied in this study. A complete list of acronyms and symbols is provided in the glossary (Sect. 6).

In order to further characterise the water-soluble organic aerosol fraction, WSM and ISOM were extracted from fine aerosol filter samples obtained during summer and winter field campaigns at the Hungarian Global Atmosphere Watch (GAW) site K-puszta. These WSM and ISOM extracts were characterised by Galambos et al. (2004) and Nyeki et al. (2003) regarding their chemical properties and volatility, respectively, and their hygroscopic properties were investigated in this study using a Hygroscopicity Tandem Differential Mobility Analyser (H-TDMA) (Rader and McMurry, 1986). Hygroscopic properties of aquatic reference fulvic and humic acids were also investigated for comparison with ISOM, since ISOM has been shown to have many chemical similarities with humic substances. Furthermore, comprehensive chemical information about the WSM samples and measured ISOM properties were used to model the hygroscopic growth of WSM in order to assess the contribution of WSOM to the total particulate water. Apart from these main topics, these experiments revealed unusual hysteresis behaviour of the humic substances and ISOM samples, which was further investigated in specific hydration/dehydration experiments.

\section{Experimental methods}

2.1 Aerosol sampling, sample preparation and chemical characterisation

Details about aerosol sampling and sample preparation may be found elsewhere (Galambos et al., 2004). Briefly, two winter and two summer, fine aerosol Hi-Vol samples $\left(\mathrm{PM}_{1.5}\right.$, particulate matter with diameter $D \leq 1.5 \mu \mathrm{m}$ ) were collected in 2001 at the continental-rural site K-puszta, Hungary. 
Samples are defined here as "KPyymmdd", indicating the sampling site and the start date of sampling (7-9 days sampling period for each sample). Aqueous WSM was obtained by soaking portions of the aerosol filters in MilliQ-water. Solid phase extraction (Varga et al., 2001) was used in a second step in order to separate water-soluble atmospheric humic matter (ISOM, less hydrophilic under acidic conditions) from inorganic salts. However, organic compounds that were very hydrophilic under acidic conditions (MHOM, "most" hydrophilic organic matter) could not be isolated from inorganic salts. Detailed chemical characterisation of $\mathrm{PM}_{1.5}$, WSM, and ISOM was performed by Galambos et al. (2004).

Figure 1 illustrates the mean composition of the investigated aerosol samples as obtained by Galambos et al. (2004). A large fraction of $\mathrm{PM}_{1.5}$ is composed of WSM ( $\left.\sim 76 \mathrm{wt} \%\right)$, including inorganic salts $(\sim 36 \mathrm{wt} \%)$ as well as WSOM $(\sim 40 \mathrm{wt} \%)$. The water-insoluble fraction $(\sim 24 \mathrm{wt} \%)$ consists of WINSOM and black carbon (BC). The sum of all carbon containing species is defined as total carbonaceous matter (TCM).

Investigated reference materials were aquatic Nordic reference fulvic and humic acids (NRFA and NRHA, respectively, International Humic Substances Society IHSS, product No. 1R105F and 1R105H, isolated from Hellrudmyra tarn, Norway) and Aldrich humic acid sodium salt (NaHA, product No. H16752, isolated from crude lignite). More information about isolation methods and chemical properties of humic substances may be found on IHSS's official web site (http://www.ihss.gatech.edu/).

\subsection{Aerosol generation}

ISOM and WSM extracts had to be transformed into aerosol particles again in order to perform hygroscopicity measurements using the H-TDMA technique. WSM solutions were directly obtained in the form of aqueous extracts (see above) with concentrations of about 140-290 mg/l. Dry ISOM extracts were dissolved in MilliQ-water, by using an ultrasonic bath for about $20 \mathrm{~min}$. Resulting concentrations were about $160-350 \mathrm{mg} / \mathrm{l}$ for the ISOM extracts. Dry NRFA, NRHA and NaHA samples were dissolved in MilliQ-water without using an ultrasonic bath. However, NRFA and NRHA could not be completely dissolved with this method. In order to remove suspended undissolved particles, all WSM, ISOM and reference solutions were filtered through a syringe membrane with a $0.22 \mu \mathrm{m}$ pore size (Millex GV $13 \mathrm{~mm}$, Millipore, USA). Artificial aerosol particles were then generated by nebulization of the solutions, and subsequently dried $(\mathrm{RH}<5 \%)$ in a silica gel diffusion dryer with a residence time of about $300 \mathrm{~s}$. The nebulizer (TSI 3076 type) was operated with artificial air $\left(80 \% \mathrm{~N}_{2}>99.999 \%, 20 \% \mathrm{O}_{2}>99.995 \%\right)$. Dried aerosol particles were neutralised and fed into the $\mathrm{H}$ TDMA for the hygroscopicity measurement. Aerosols generated with this procedure are internally mixed, and the chem-

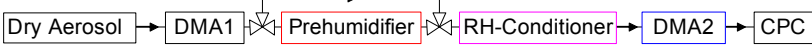

Fig. 2. Hygroscopicity Tandem Differential Mobility Analyser with optional prehumidifier. The prehumidifier is usually set to $\sim 95 \%$ $\mathrm{RH}$, whereas the $\mathrm{RH}$-conditioner can be set to $\mathrm{RH}$ values between $\sim 5 \%$ and $\sim 95 \%$. The prehumidifier is bypassed or included to measure hygroscopic growth factors during hydration or dehydration, respectively (see text and Fig. 3 for details).

ical composition of the individual particles is representative of the $\mathrm{PM}_{1.5}$ average WSM or ISOM composition.

\subsection{Hygroscopicity measurement}

The hygroscopic growth factor $g$ of a particle is defined as

$g(\mathrm{RH})=\frac{D(\mathrm{RH})}{D_{0}}$,

where $D_{0}$ is the particle dry diameter, and $D(\mathrm{RH})$ is its diameter at a specific RH. The hygroscopic growth factor $g$ indicates the relative size increase of particles due to water uptake. The H-TDMA system (Fig. 2) is described in detail by Weingartner et al. (2002) and Gysel et al. (2002). An additional prehumidifier was used in this study, and is described later. Briefly, a monodisperse fraction $\left(D_{0} \approx 100 \mathrm{~nm}\right)$ of dried neutralised $\left({ }^{85} \mathrm{Kr}\right.$ bipolar charger) aerosol particles was selected with a first DMA (DMA1; TSI 3071). This monodisperse aerosol was then humidified, and the resulting particle size after humidification was measured by scanning the whole size range with a second DMA (DMA2) and a Condensation Particle Counter (CPC, TSI model 3022).

Mean diameter $D_{m}$ and standard deviation $\sigma$ (normal distribution) were obtained using an inversion algorithm based on the original TDMAFIT QBASIC program by Stolzenburg and McMurry (1988). The H-TDMA was kept at a constant temperature $T \sim 25^{\circ} \mathrm{C}$ (DMA2 was submersed in a well-mixed water bath), and the relevant $\mathrm{RH}\left(\mathrm{RH}_{D M A 2}\right)$ was determined by measurement of the system temperature and DMA2 sheath air dew point using a dew point mirror (Edge Tech, Model DewPrime II). At constant conditions the $\mathrm{RH}$ accuracy is $\triangle \mathrm{RH}_{D M A 2}= \pm 1.2 \%$ at $95 \% \mathrm{RH}$. Both DMAs were operated with a closed loop sheath air setup and critical orifices were used to control flow rates, which allowed the growth factor to be determined with an accuracy of $\Delta g \approx \pm 0.003$ in terms of mobility diameters. However, larger uncertainties due to unknown shape effects may be introduced whenever mobility equivalent diameters are converted to volume equivalent diameters. The humidification section consisted of an optional prehumidifier and a followon $\mathrm{RH}$-conditioner. $\mathrm{RH}$ values after the prehumidifier $\left(\mathrm{RH}_{P}\right)$ and after the $\mathrm{RH}$-conditioner $\left(\mathrm{RH}_{C}\right)$ were also monitored using capacitive RH sensors. Due to the closed loop setup, $\mathrm{RH}_{D M A 2}$ equilibrates with $\mathrm{RH}_{C}$ after a time delay of a few minutes for small $\mathrm{RH}_{C}$ changes (cf. Fig. 3). Approximate 


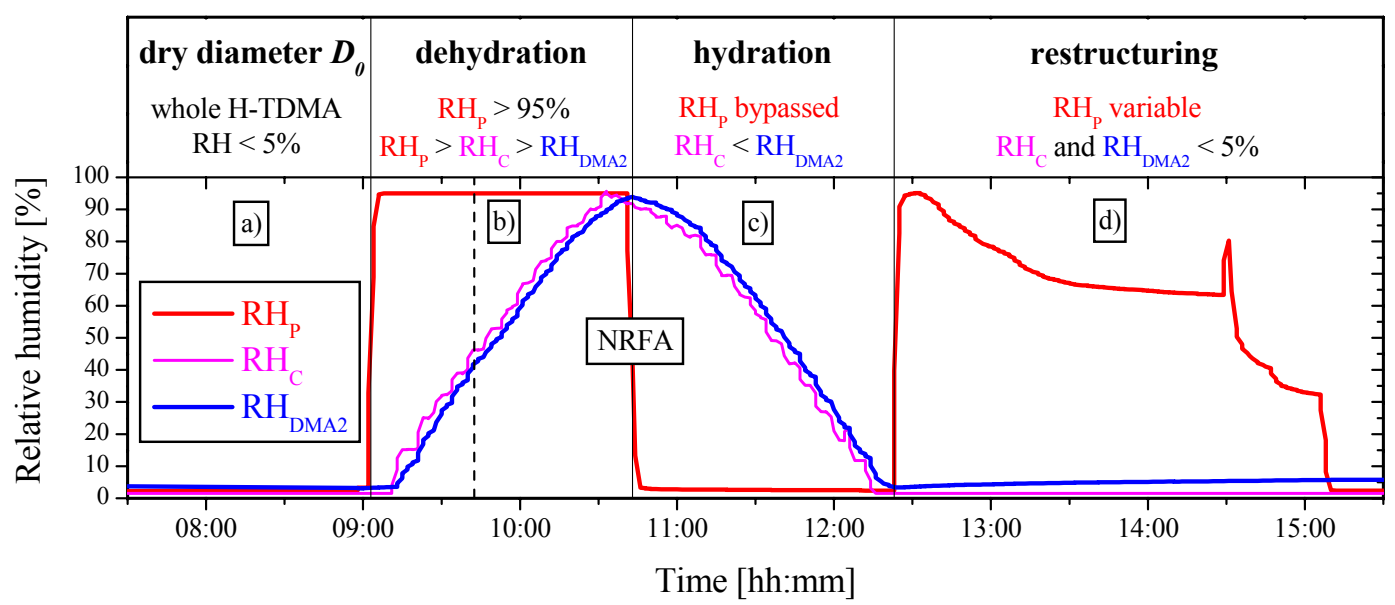

Fig. 3. Typical measurement cycle with the H-TDMA (NRFA sample). Abbreviations are RH after prehumidifier $\left(\mathrm{RH}_{P}\right)$, $\mathrm{RH}_{\text {after }} \mathrm{RH}-$ conditioner $\left(\mathrm{RH}_{C}\right)$, and $\mathrm{RH}$ in DMA2 $\left(\mathrm{RH}_{D M A 2}\right)$. Dry, monodisperse particles initially selected in DMA1 are then successively exposed to $\mathrm{RH}_{P}, \mathrm{RH}_{C}$, and $\mathrm{RH}_{D M A 2}$. (Line colours in this figure correspond to instrument section colouring in Fig. 2.) The four applied instrument modes are (a) measurement of dry diameter $D_{0}$, (b) growth factor $g_{d e h y}\left(\mathrm{RH}_{D M A 2}\right)$ during dehydration, $(\mathbf{c})$ growth factor $g_{h y d r}\left(\mathrm{RH}_{D M A 2}\right)$ during hydration, and (d) restructuring $g_{\text {restr }}\left(\mathrm{RH}_{P}\right)$. See text for detailed description of instrument modes and for discussion of the dashed line at 9:42.

residence times in the instrument are $3 \mathrm{~s}$ after the prehumidifier, $5 \mathrm{~s}$ after the RH-conditioner, and $8 \mathrm{~s}$ in DMA2. Four measurement modes can be selected depending on the settings of $\mathrm{RH}_{P}$ and $\mathrm{RH}_{C}$. Figure 3 shows a time series of $\mathrm{RH}_{P}, \mathrm{RH}_{C}$, and $\mathrm{RH}_{D M A 2}$ during a complete measurement cycle (NRFA). The four different H-TDMA modes are:

- Dry reference diameter $D_{0}$ (Fig. 3a): This mode is used to measure the dry reference diameter $D_{0}$ of the particles selected with the first DMA. Both humidifiers are switched off. The RH throughout the whole H-TDMA equilibrates with the incoming dry aerosol air, i.e. $\mathrm{RH}_{P}$, $\mathrm{RH}_{C}$, and $\mathrm{RH}_{D M A 2}$ are lower than $5 \%$. In this case the particles do not undergo any change, and the diameter $D_{0}$ measured in DMA2 represents precisely the (electrical mobility) diameter of the dry particles selected with DMA1. $D_{0}$ is used as the reference diameter for all experimental growth factors $g$ (cf. Eq. 1).

- Growth factors during dehydration $g_{d e h y}(\mathrm{RH})$ (Fig. 3b): This mode is used to measure hygroscopic growth factors during dehydration. The prehumidifier is set to a high $\mathrm{RH}\left(\mathrm{RH}_{P} \geq 95 \%\right)$, and $\mathrm{RH}_{C}$ is successively increased. In this case $\mathrm{RH}_{P} \geq \mathrm{RH}_{C} \geq \mathrm{RH}_{D M A 2}$, i.e. the particles are dehydrated since they undergo strictly decreasing RH conditions, while passing through the instrument. Hence growth factors are labelled as $g_{\text {dehy }}\left(\mathrm{RH}_{D M A 2}\right) . \mathrm{RH}_{D M A 2}$ increases slowly during the measurement of growth factors at dehydration since the aerosol air introduces additional humidity in the closedloop sheath air flow $\left(\mathrm{RH}_{C} \geq \mathrm{RH}_{D M A 2}\right)$.

- Growth factors during hydration $g_{h y d r}(\mathrm{RH})$ (Fig. 3c): This mode is used to measure hygroscopic growth factors during hydration. The prehumidifier is bypassed $\left(\mathrm{RH}_{P} \leq 5 \%\right)$, and $\mathrm{RH}_{C}$ is successively decreased. In this case $\mathrm{RH}_{P} \leq \mathrm{RH}_{C} \leq \mathrm{RH}_{D M A 2}$, i.e. the particles are hydrated since they undergo strictly increasing $\mathrm{RH}$ conditions, while passing through the instrument. Hence growth factors are labelled as $g_{h y d r}\left(\mathrm{RH}_{D M A 2}\right)$. $\mathrm{RH}_{D M A 2}$ decreases slowly during the measurement of growth factors at hydration since the aerosol air reduces the humidity of the closed-loop sheath air flow $\left(\mathrm{RH}_{C} \leq \mathrm{RH}_{D M A 2}\right)$.

- RH-dependent restructuring of the particles $g_{\text {restr }}(\mathrm{RH})$ (Fig. 3d): This measurement provides the so-called restructuring factor $g_{\text {restr }}\left(\mathrm{RH}_{P}\right)$, i.e. the size change of initially dry particles if they are exposed to a certain $\mathrm{RH}_{P}$, and dried up again. The $\mathrm{RH}$ in the prehumidifier is varied, while the $\mathrm{RH}$-conditioner is used as a dryer $\left(\mathrm{RH}_{C}\right.$ and $\left.\mathrm{RH}_{D M A 2} \leq 5 \%\right)$.

As an example the dashed line at 9:42 in Fig. $3 b$ indicates the measurement of the growth factor during dehydration $g_{\text {dehy }}$ at $41 \% \mathrm{RH}$ : The dry, monodisperse particles of known size are first exposed to $94 \% \mathrm{RH}$ in the prehumidifier (intersection with red line), then to $44 \% \mathrm{RH}$ in the $\mathrm{RH}$-conditioner (intersection with magenta line), and the resulting size is finally measured in DMA2 at $41 \%$ RH (intersection with blue line).

\section{Theory}

Three fundamentally different models are used in this study. The suitability of the theoretical ideal solution model and the empirical $\gamma$-model to provide parameterisations of the 
experimentally observed hygroscopic growth characteristics is compared and evaluated. In addition, the ideal solution model provides a rough estimate of the molar mass of the ISOM. The aim of the more sophisticated mixed particle model is to conduct a hygroscopicity closure study, i.e. to investigate the individual contributions of the inorganic, ISOM, and MHOM fractions to the hygroscopic growth of the WSM samples.

\subsection{Ideal solution model}

The hygroscopic growth of soluble particles as a function of RH is described by the Köhler theory (Pruppacher and Klett, 1997; Seinfeld and Pandis, 1998). For an ideal solution the equilibrium $\mathrm{RH}$ above a flat surface is equal to the mole fraction $x_{w}$ of water in the solution (Raoult's law). Generally Raoult's law is valid for diluted solutions, i.e. large growth factors close to or above water vapour saturation, while care has to be taken at lower RH. In this study the ideal solution model is used as the best possible approach to describe the hygroscopic growth of ISOM samples, since no information about real water activity values is available. For the case of a spherical droplet of diameter $D$, the Kelvin correction factor $S_{\text {Kelvin }}$ accounts for the water vapour pressure increase over a curved surface. The resulting relation between the equilibrium $\mathrm{RH}$ and the droplet diameter $D$ for an ideal solution is (Köhler equation):

$\mathrm{RH}=x_{w}(D) \cdot S_{K e l v i n}(D)=x_{w}(D) \cdot \exp \left(\frac{4 M_{w} \zeta}{R T \rho_{w} D}\right)$,

where $M_{w}$ and $\rho_{w}$ are the molar mass and the density of water, $\zeta$ is the surface tension of the solution, $R$ is the ideal gas constant, and $T[\mathrm{~K}]$ is the temperature. Due to lack of information the solution surface tension $\varsigma$ is approximated by the surface tension of pure water. This has less effect on theoretical growth factors $g_{t h}$ under subsaturated RH conditions, but the use of Eq. (2) under supersaturated conditions to estimate critical supersaturation and diameter values would profit from more precise $\varsigma$ values. Generally the mole fraction of water $x_{w}$ is defined as:

$x_{w}=\frac{n_{w}}{n_{w}+n_{s}}$,

where $n_{w}$ is the molar number of water molecules and $n_{s}$ is the molar number of solute molecules (or ions if the molecules dissociate in aqueous solution). The mole fraction $x_{w}$ of a droplet depends on $g_{t h}$ and the effective molar volume of solute molecules (or ions) $v_{s}$ :

$x_{w}\left(g_{t h}, v_{s}\right)=\frac{g_{t h}^{3}-1}{g_{t h}^{3}-1+\frac{M_{w}}{\rho_{w} v_{s}}}$.

Equation (4) includes the approximation that the volume change due to mixing is zero, independent of solution concentration, i.e. the solute and solvent volumes are additive.

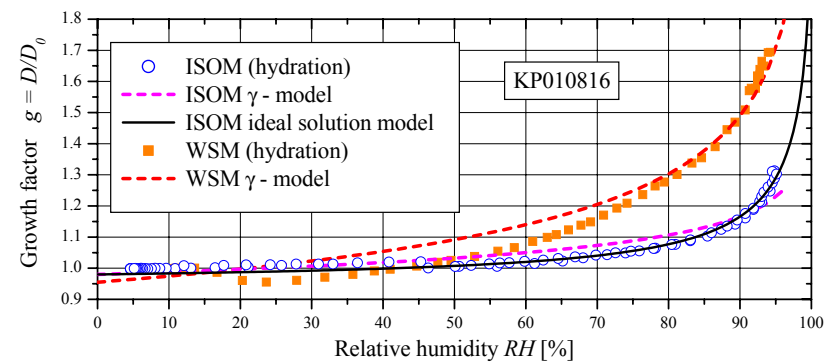

Fig. 4. Hygroscopic growth factors of KP010816-ISOM and -WSM samples.

Equation (2) determines the equilibrium mole fraction $x_{w}$ of an ideal solution at a given RH, and Eq. (4) relates this concentration to the corresponding theoretical hygroscopic growth factor $g_{t h} . v_{s}$, the only parameter determining the hygroscopicity of an ideal solution, is used to fit theoretical growth curves to experimental results obtained for ISOM. $v_{s}$ depends on the effective molar mass $M_{s}$, density $\rho_{s}$, and van't Hoff factor $i_{s}$ of the solute:

$v_{s}=\frac{M_{s}}{\rho_{S} \cdot i_{S}}$

The van't Hoff factor $i_{s}$ is equal to the number of dissociated ions per molecule. Equation (5) was used to obtain an estimate of $M_{s}$ from fitted $v_{s}$ values, whereas values assumed for ISOM density $\left(\rho_{I S O M}=1500 \mathrm{~kg} / \mathrm{m}^{3}\right)$ and van't Hoff factor $\left(i_{I S O M}=1\right)$ are discussed below.

\subsection{Empirical $\gamma$-model}

The empirical $\gamma$-model is frequently used in literature (Swietlicki et al., 2000; Peng et al., 2001; Weingartner et al., 2002; Massling et al., 2003) to describe the hygroscopic growth of ambient as well as that of organic particles. It is a simple one-parameter relation:

$g_{t h}=(1-\mathrm{RH} / 100 \%)^{-\gamma}$,

where $\gamma$ is the model parameter. Even though this model is restricted to $\mathrm{RH}<100 \%$, it is quite useful to quantify the hygroscopic growth of aerosol particles. $\gamma$ was determined for all samples by fitting the model to experimental growth factors at $90 \% \mathrm{RH}$. The overall RH dependence of experimental growth factors measured in this study is generally better reproduced by the ideal solution model compared to the $\gamma$-model (see below), but nevertheless the latter is included here, since it allows a comparison with results from other studies.

\subsection{Mixed particle model}

The hygroscopic growth factor $g_{W S M}$ of a mixed WSM particle can be estimated from the growth factors $g_{\text {Inorg }}, g_{I S O M}$, and $g_{\text {МНОM }}$ of "pure" inorganic, ISOM, and MHOM particles, and from their respective volume fractions $\varepsilon_{\text {Inorg }}$, 


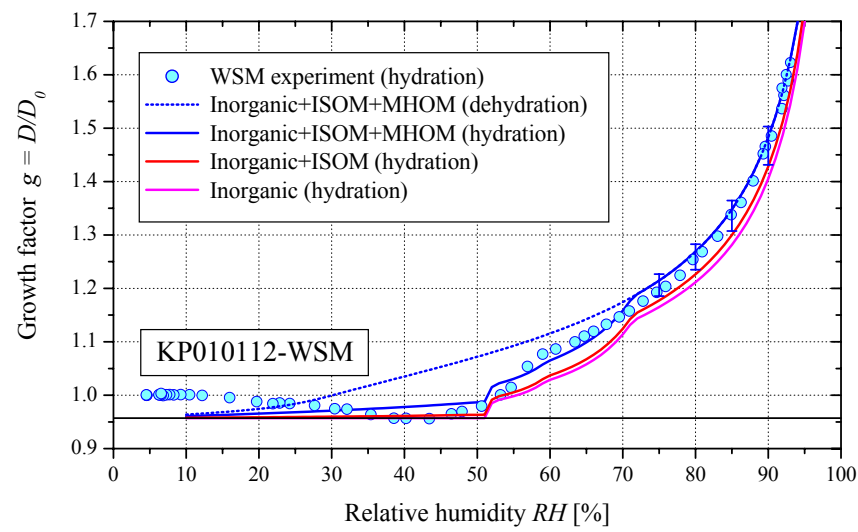

Fig. 5. Hygroscopicity closure for the KP010112-WSM sample (winter). Measured growth factors are shown as points, lines represent model predictions for different model assumptions (see text for details). The contribution of inorganic salts was calculated from the chemical composition, ISOM hygroscopicity was measured in pure form, and the hygroscopicity of MHOM was assumed to correspond to a $\gamma_{\text {M HOM }}=0.163$ ( $\gamma$-model), which is a typical value for highly soluble organic acids.

$\varepsilon_{I S O M}$, and $\varepsilon_{M H O M}$ in the mixed particle:

$$
\begin{aligned}
g_{W S M}= & \left(\varepsilon_{\text {Inorg }} g_{\text {Inorg }}^{3}+\varepsilon_{\text {ISOM }} g_{\text {ISOM }}^{3}\right. \\
& \left.+\varepsilon_{\text {M HOM }} g_{\text {MHOM }}^{3}\right)^{1 / 3} .
\end{aligned}
$$

Equation (7) is equivalent to the Zdanovskii-StokesRobinson relation (ZSR relation, Chen et al., 1973), it includes the approximation of independent hygroscopic behaviour of the inorganic, ISOM, and MHOM fractions. Hygroscopic properties of mixtures of carboxylic, dicarboxylic, or multifunctional organic acids with single inorganic salts under subsaturated RH conditions have been previously investigated in laboratory experiments by Hansson et al. (1998), Cruz and Pandis (2000), Lightstone et al. (2000), Choi and Chan, (2002b), Hämeri et al. (2002), and Chan and Chan (2003). Experimental results often indicate fair agreement with ZSR predictions, but according to a more detailed analysis of literature data (Chan and Chan, 2003) positive or negative interactions between organic and inorganic compounds are likely, depending on mixed species and concentrations.

In this study, $g_{I S O M}(\mathrm{RH})$ is experimentally determined. The growth factor of the MHOM fraction is not known, but a value of $\gamma=0.163$ (empirical $\gamma$-model) is representative of highly soluble organic acids (Peng et al., 2001) such as malonic acid (dicarboxylic acid), citric acid, malic acid and tartaric acid (hydroxy-carboxylic acids). Hence growth factors calculated with $\gamma_{M H O M}=0.163$ are used as a best guess for $g_{M H O M}(\mathrm{RH})$. The composition of the inorganic fraction is known from the chemical analysis of the WSM samples (Galambos et al., 2004). Excess anions were compensated by $\mathrm{H}^{+}$to adjust the charge balance. The thermodynamic aerosol inorganics model (AIM) by Clegg et al. (1998; http://

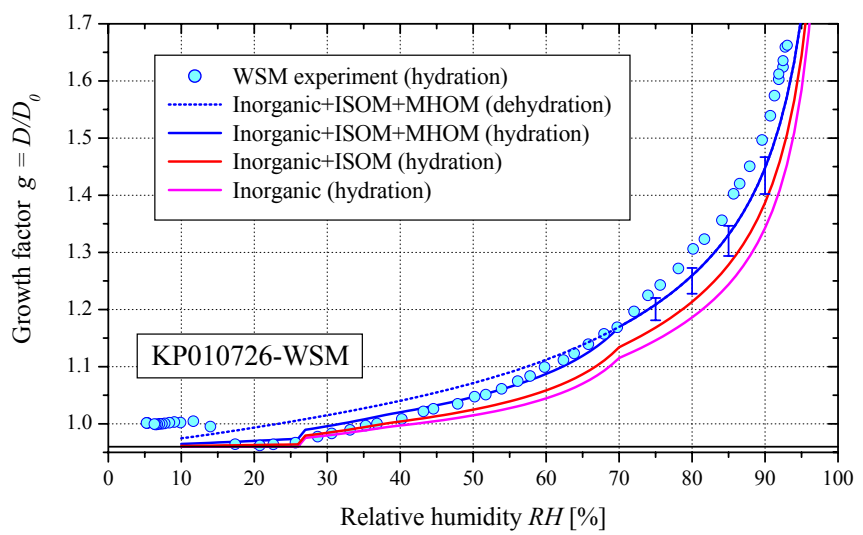

Fig. 6. Same as Fig. 5, but for the KP010726-WSM sample (summer).

www.hpc1.uea.ac.uk/ e770/aim/aim.htm) for the $\mathrm{H}^{+}-\mathrm{NH}_{4}^{+}$$\mathrm{Na}^{+}-\mathrm{SO}_{4}^{2-}-\mathrm{NO}_{3}^{-}-\mathrm{Cl}^{-}-\mathrm{H}_{2} \mathrm{O}$ system (AIM2-III) was used to determine corresponding growth factors $g_{\text {Inorg }}$. The minor cations $\mathrm{Ca}^{2+}$ and $\mathrm{K}^{+}$were replaced by a proper amount of $\mathrm{Na}^{+}$since they are not supported by AIM2-III.

The overall hygroscopic growth of the WSM samples was predicted (Eq. 7) from the growth factors $g_{\text {Inorg }}, g_{I S O M}$, and $g_{M H O M}$ of the three WSM fractions (curves "Inorganic+ISOM+MHOM" in Figs. 5 and 6, discussion below). The contribution of the inorganic fraction (curve "Inorganic") was determined by treating the ISOM and MHOM fractions as inert with respect to water uptake (i.e. $g_{I S O M}=1$ and $g_{\text {M }}$ OM $=1$ ). Analogously, the curve "Inorganic+ISOM" was calculated by treating MHOM as inert (i.e. $g_{M \text { н }}=1$ ). A discussion of assumptions and approximations which affect all these model curves follows.

The conversion of measured carbon mass fractions into organic volume fractions $\left(\varepsilon_{I S O M}\right.$, and $\left.\varepsilon_{M H O M}\right)$ depends on the organic matter to carbon mass conversion factors (see Sect. 4.1) and on the densities $\rho_{\text {Inorg }}, \rho_{I S O M}$, and $\rho_{M \text { M }}$. Due to a lack of information a value of $1500 \mathrm{~kg} / \mathrm{m}^{3}$, which is appropriate for carboxylic and multifunctional organic acids (Saxena et al., 1995; Peng et al., 2001) was assumed for $\rho_{I S O M}$, and $\rho_{\text {M Ном }}$. The density $\rho_{\text {Inorg }}$ was determined from the volume weighted average of the individual salts, which are present in the dry particle according to the AIM output. However, salts effectively present in the solid particle may differ from the thermodynamic AIM prediction, which is a Gibbs free energy minimization, but fortunately $\rho_{\text {Inorg }}$ depends only slightly on the various salt combinations that are theoretically possible for a given ion composition. The solution density $\rho_{\text {sol }}$ is approximated by the ratio of total mass to total volume of added inorganic, ISOM, MHOM and water fractions, assuming that the volume of mixing is zero. The replacement of $\mathrm{Ca}^{2+}$ and $\mathrm{K}^{+}$cations by $\mathrm{Na}^{+}$has little effect on $g_{\text {Inorg }}$ due to their small abundance compared to the major ions. Apart from the unknown accuracy of the ZSR relation for these organic/inorganic WSM mixtures, modelled 
Table 1. Aerosol chemical composition of Hi-Vol atmospheric filter samples.

\begin{tabular}{lccccccc}
\hline & $\mathrm{PM}_{1.5} *$ & $\mathrm{TCM}$ & inorg. salts & $\begin{array}{c}\text { WSM of } \\
\mathrm{PM}_{1.5}\end{array}$ & $\begin{array}{c}\text { inorg. salts } \\
\text { of WSM }\end{array}$ & $\begin{array}{c}\text { ISOM } \\
\text { of WSM }\end{array}$ & $\begin{array}{c}\text { MHOM } \\
\text { of WSM }\end{array}$ \\
sample & $\mu \mathrm{g} / \mathrm{m}^{3}$ & $\mu \mathrm{g} / \mathrm{m}^{3}$ & $\mu \mathrm{g} / \mathrm{m}^{3}$ & wt $\%$ & wt $\%$ & wt \% & wt \% \\
\hline KP010112 & 33.5 & 23.4 & 10.1 & 65 & 47 & 36 & 17 \\
KP010126 & 13.7 & 8.5 & 5.2 & 72 & 53 & 33 & 14 \\
KP010726 & 11.7 & 7.4 & 4.3 & 89 & 42 & 40 & 18 \\
KP010816 & 21.4 & 13.4 & 8.0 & 80 & 47 & 36 & 17 \\
\hline
\end{tabular}

* $\mathrm{PM}_{1.5}$ was calculated under the assumption that the aerosol is composed of exclusively carbonaceous matter and water-soluble inorganic salts.

growth curves are most sensitive to the value of $\rho_{I S O M}$, since it directly changes the volume fraction of less hygroscopic ISOM $\left(\varepsilon_{I S O M}\right)$ and that of distinctly more hygroscopic inorganic salts $\left(\varepsilon_{\text {Inorg }}\right)$ in opposite directions.

\subsection{Mobility correction factor $f$}

Equations (2) and (4) (ideal solution model), Eq. (6) $(\gamma$ model), and Eq. (7) (mixed particle models) describe theoretical growth factors $g_{t h}$ in terms of volume equivalent diameters. Experimental results achieved with the H-TDMA are measured and presented in terms of electrical mobility diameters. To compare modelled growth factors $g_{\text {mod }}$ with experimental results, a mobility correction factor $f$ is introduced for $g_{t h}$ :

$g_{\text {mod }}=f \cdot g_{t h}$.

Possible effects included in $f$ are:

- Liquid particles at sufficiently high RH are spherical and compact, and hence volume equivalent and measured electrical mobility diameters are equal. Dry particles were seen to be nearly spherical (Scanning Electron Microscopy (SEM) micrographs), but cracks or cavities in the particle structure cannot be excluded on the basis of these pictures and are possible, since large droplets leaving the nebuliser are suddenly exposed to very low RH in the diffusion dryer, leading to very fast water evaporation and crystallization of the particles. Such particles have dynamic shape factors larger than 1 , resulting in dry mobility diameters, $D_{0}$, larger than the corresponding volume equivalent diameters. Theoretical growth factors have to be adjusted with a correction factor $f \leq 1$ to account for such an overestimation of experimental dry diameters $D_{0}$.

- The correction factor $f$ also accounts for possible deficiencies of the assumption that the volume of mixing of deliquescent particles is zero, i.e. that the individual species volumes are additive in solution.
For the ISOM and the reference humic substances the correction factor $f$ is chosen as the experimental value

$f=g_{\text {dehy }}\left(\mathrm{RH}_{D M A 2} \leq 5 \%\right) \equiv g_{\text {restr }}\left(\mathrm{RH}_{P} \geq 95 \%\right)$,

since it is assumed that restructured particles at $\mathrm{RH}_{D M A 2} \leq 5 \%$ are spherical and compact after the previous cycle of deliquescence $\left(\mathrm{RH}_{P} \geq 95 \%\right)$ in the prehumidifier and subsequent drying in the $\mathrm{RH}$-conditioner $\left(\mathrm{RH}_{C} \leq 5 \%\right)$. Since no growth factors at dehydration are available for the WSM samples, the correction factor $f$ is chosen as the smallest measured growth factor at hydration in this case. The mobility correction factor is always applied to the ideal solution model, the empirical $\gamma$-model, and the mixed particle model. However, modelled growth factors $g_{\text {mod }}$ corrected with a $\mathrm{RH}$ independent mobility correction factor $f$ are comparable only with experimental results of deliquescent particles at sufficiently high RH or at dehydration, since the dynamic shape factor does not change substantially before deliquescence.

\section{Results and discussion}

\subsection{Chemistry of atmospheric samples}

A summary of $\mathrm{PM}_{1.5}$ chemical composition as determined for the investigated samples by Galambos et al. (2004) is given in Table 1. It is assumed that $\mathrm{PM}_{1.5}$ at $\mathrm{K}$-puszta is dominated by inorganic salts and carbonaceous matter (i.e. $\mathrm{PM}_{1.5}=$ inorganic salts+TCM), as it has been found in earlier mass closure experiments by Zappoli et al. (1999). Total mass concentrations of inorganic salts were directly measured using capillary electrophoresis while mass concentrations of carbonaceous species were determined by multiplication of the measured carbon mass concentration with mass conversion factors suitable for each class of compounds. ISOM mass conversion factors were between 1.81 and 1.91 as determined for each sample by elemental analysis (Galambos et al., 2004). General conversion factors of 2.3, 1.6 and 1.1 were applied for MHOM, WINSOM, and BC, respectively (Kiss et al., 2002). The apportionment of total 
Table 2. Hygroscopic growth factors, deliquescence relative humidity and model parameters.

\begin{tabular}{lccccc}
\hline & $\begin{array}{c}\text { growth } \\
\text { factor }\end{array}$ & deliquescence & $\begin{array}{c}\text { mobility } \\
\text { correction }\end{array}$ & $\gamma$-model & $\begin{array}{c}\text { ideal solution } \\
\text { model }\end{array}$ \\
& $\begin{array}{c}g(90 \%) \\
(-)\end{array}$ & $\begin{array}{c}\mathrm{DRH}^{\circ} \\
(\%)\end{array}$ & $\begin{array}{c}f \\
(-)\end{array}$ & $\begin{array}{c}\gamma^{*} \\
(-)\end{array}$ & $\begin{array}{c}M^{\dagger} \\
(\mathrm{kg} / \mathrm{kmol})\end{array}$ \\
\hline KP010112-ISOM & 1.08 & $50-60$ & 0.96 & 0.050 & 495 \\
KP010126-ISOM & 1.11 & $40-55$ & 0.97 & 0.059 & 405 \\
KP010726-ISOM & 1.16 & $30-45$ & 0.98 & 0.073 & 315 \\
KP010816-ISOM & 1.17 & $45-55$ & 0.98 & 0.075 & 300 \\
KP010112-WSM & 1.48 & n.a. & 0.96 & 0.189 & n.a. \\
KP010126-WSM & 1.52 & n.a. & 0.95 & 0.203 & n.a. \\
KP010726-WSM & 1.52 & n.a. & 0.96 & 0.199 & n.a. \\
KP010816-WSM & 1.49 & n.a. & 0.96 & 0.193 & n.a. \\
NaHA & 1.18 & $60-75$ & 0.94 & 0.097 & n.a. \\
NRFA & 1.13 & $75-85$ & 1.01 & 0.049 & 510 \\
NRHA & 1.06 & $85-95$ & 0.98 & 0.034 & 765 \\
\hline
\end{tabular}

- The given RH values indicate the range between deliquescence onset and completion.

* The model parameter $\gamma$ was fitted to the experimental growth factor at $90 \% \mathrm{RH}$.

$\dagger M$ is obtained by fitting the ideal solution model to experimental results. The given $M$ estimates are only valid under the following assumptions: The density of the organic solute is $\rho=1500 \mathrm{~kg} / \mathrm{m}^{3}$, and the van't Hoff factor of the organic molecules is $i=1$ (see text for the discussion of these assumptions).

$\ddagger$ Not applicable.

water-insoluble carbonaceous matter into WINSOM and BC was not determined for all samples (Galambos et al., 2004), but this does not affect mass fractions of WSOM with respect to WSM which are important for growth modelling (see below). Thus, only TCM (=WSOM+WINSOM+BC) mass concentrations are somewhat uncertain for KP010126 and KP010726.

About $70 \%$ and $85 \%$ of $\mathrm{PM}_{1.5}$ in winter and summer samples, respectively, are water-soluble. The water-soluble mass itself is on average composed of $47 \%$ inorganic salts, $36 \%$ ISOM, and $17 \%$ MHOM with small seasonal differences except for a small trend towards a larger organic fraction in summer. On the basis of a comparison with previous aerosol samples from K-puszta (Kiss et al., 2002), the present samples are considered to be representative in terms of chemical properties. However, small differences observed between summer and winter samples cannot be definitely attributed to the seasonal influence based on the small number of samples.

\subsection{Hygroscopicity of atmospheric WSM and ISOM sam- ples}

Growth factors $g$, mobility correction factors $f$ and model parameters $\gamma$ of all investigated WSM and ISOM extracts are listed in Table 2. In the following, results will be discussed with respect to humidograms obtained for each summer and winter sample. The hygroscopic behaviour of the KP010816-ISOM and -WSM extracts (summer sample) during hydration is illustrated in Fig. 4. WSM is seen to be dis- tinctly more hygroscopic compared to ISOM. Starting at dry conditions, there is first a small size decrease at around $20 \%$ RH to a growth factor of $g_{W S M}=0.96$. This small restructuring is attributed to a mobility effect, i.e. a reduction of the dynamic shape factor due to microstructural rearrangement. Similar effects were observed for e.g. pure $\mathrm{NaCl}$ particles in previous studies (Krämer et al., 2000; Hämeri et al., 2001; Gysel et al., 2002). The presence of organics with low deliquescence RH might induce this microstructural rearrangement of WSM particles at lower RH compared to pure $\mathrm{NaCl}$ particles. The smallest detected growth factor at low $\mathrm{RH}$ is chosen as the mobility correction factor $f$ for the WSM samples (see above). At $\mathrm{RH}>25 \%$ there is continuous water uptake onto WSM particles, resulting in a growth factor of $g_{W S M}=1.49$ at $90 \% \mathrm{RH}$. While the initial size decrease at low RH is common for all four WSM extracts, the two winter samples (Fig. 5 shows one example) exhibited a more gradual growth characteristic between 40 and $80 \%$ RH in contrast to the continuous growth of both summer samples (Figs. 4 and 6). This different deliquescence behaviour between summer and winter samples probably arises from seasonal differences of the inorganic composition. For example ammonium nitrate is practically absent in summer (Galambos et al., 2004). At $\mathrm{RH}>70 \%$, hygroscopic growth factors are comparable for summer and winter WSM extracts.

ISOM exhibits no distinct growth below $50 \%$, but the particle size increases continuously at $\mathrm{RH}>50 \%$, resulting in growth factors of $g_{I S O M}=1.11$ and 1.17 at 85 and $90 \% \mathrm{RH}$, 
Table 3. Model accuracy at $90 \%$ RH (mixed particle model) and attribution of particulate water $w$ to the different fractions of WSM.

\begin{tabular}{lccccc}
\hline sample & model accuracy* & $\begin{array}{c}\text { inorganic salts } \\
w_{\text {Inorg }}\end{array}$ & $\begin{array}{c}\text { WSOM } \\
w_{\text {WSOM }}\end{array}$ & $\begin{array}{c}\text { ISOM } \\
w_{\text {ISOM }}\end{array}$ & $\begin{array}{c}\text { MHOM }^{\dagger} \\
w_{M H O M}\end{array}$ \\
\hline KP010112-WSM & $1 \%$ & $80 \%$ & $20 \%$ & $6 \%$ & $14 \%$ \\
KP010126-WSM & $-5 \%$ & $79 \%$ & $21 \%$ & $6 \%$ & $15 \%$ \\
KP010726-WSM & $-18 \%$ & $59 \%$ & $41 \%$ & $9 \%$ & $32 \%$ \\
KP010816-WSM & $-12 \%$ & $65 \%$ & $35 \%$ & $9 \%$ & $26 \%$ \\
\hline
\end{tabular}

\footnotetext{
* Difference between prediction of the complete mixed particle model ("Inorganic+ISOM+MHOM") and measured water uptake in terms of volume.

$\dagger$ Estimate from difference between measured value and model prediction for the inorganic+ISOM fraction.
}

respectively. ISOM was slightly more hygroscopic in summer than in winter (see $g_{I S O M}$ in Table 2). Possible reasons for this difference are varying precursor substances, i.e. more anthropogenic influence in winter, and faster (photo)chemical oxidation in summer. Small differences were also observed in the chemical composition, as total mass to carbon mass ratios were slightly larger in the summer ISOM samples (Galambos et al., 2004). However, the number of investigated samples was too small to definitely attribute these small differences to the seasonal influence. Hygroscopic growth factors of ISOM are comparable to the hygroscopicity of secondary organic aerosol mass, which was obtained in recent smog chamber studies by oxidation of $\alpha$-pinene, $\beta$-pinene, limonene, $\mathrm{m}$-xylene, or 1,3,5-trimethylbenzene (Cocker III et al., 2001a; Cocker III et al., 2001b; Saathoff et al., 2003; Virkkula et al., 1999), but it is distinctly lower than the hygroscopic growth of highly soluble organic acids such as malonic acid, citric acid, malic acid and tartaric acid (Peng et al., 2001).

\subsection{Hygroscopicity closure for atmospheric WSM}

Figures 5 and 6 illustrate the results of the hygroscopicity closure for the KP010112-WSM and KP010726-WSM extracts, which are representative of investigated winter and summer samples, respectively. Experimental results are shown as points ("WSM experiment") and model predictions obtained with different versions of the mixed particle model (Sect. 3.3) are shown as lines. The complete mixed particle model (curve "Inorganic+ISOM+MHOM") accounts for the water uptake by inorganic salts, ISOM, and uses an estimate $\left(\gamma_{\text {M HOM }}=0.163\right)$ for the hygroscopicity of MHOM, which is the only remaining undetermined WSM fraction. The curve "Inorganic" shows the water uptake as predicted for the inorganic salts only, i.e. ISOM and MHOM are treated as inert in these model calculations, and similarly the curve "Inorganic+ISOM" shows the water uptake as predicted for the inorganic salts and ISOM without a contribution of the MHOM. It can be seen from Figs. 5 and 6, that the models "Inorganic" and "Inorganic+ISOM" cannot explain the observed hygroscopic growth completely. Only the complete mixed particle model "Inorganic+ISOM+MHOM", which accounts also for the water uptake of the MHOM, agrees well with experimental results. Total water uptake (by volume) predicted with this model is $1 \%$ larger to $5 \%$ smaller in winter and $12 \%$ to $18 \%$ smaller in summer compared to experimental results (see also second column in Table 3). The reason for this slightly lower model accuracy in summer is unclear, since the inorganic to organic mass ratio of WSM samples is quite independent of season. However, possible reasons could be a greater effective MHOM hygroscopicity in summer analogous to the greater ISOM hygroscopicity, a higher average WSOM density, or stronger positive interactions between inorganic and organic solutes. As discussed above, modelled growth curves are most sensitive to the assumption of ISOM density $\rho_{I S O M}$, apart from uncertainties of the estimated MHOM hygroscopicity, the ZSR relation accuracy, and real solution densities. Hence $\rho_{\text {ISOM }}$ was varied from 1000 to $1800 \mathrm{~kg} / \mathrm{m}^{3}$ to indicate the model uncertainty at selected RHs (error bars of curve "Inorganic+ISOM+MHOM").

The mixed particle model was also used to estimate the individual contributions of the inorganic, ISOM, and MHOM fractions to the overall hygroscopic growth of the WSM particles. Table 3 shows the percentages $w$ of water associated with the individual WSM fractions at $90 \% \mathrm{RH}$ for all four samples. The measured water uptake is defined as $w_{\text {Meas }}=100 \%$ and the particulate water associated with inorganic salts $\left(w_{\text {Inorg }}\right)$ is obtained with the model "Inorganic". The excess water, i.e. the particulate water which cannot be explained by the water uptake of inorganic salts, is attributed to the WSOM $\left(w_{W S O M}=w_{\text {Meas }}-w_{\text {Inorg }}\right)$. The contributions of ISOM and MHOM are obtained with $w_{I S O M}=w_{\text {Inorg }+I S O M}-w_{\text {Inorg }}$ and $w_{M H O M}=w_{W S O M}-w_{I S O M}$, respectively. The inorganic fraction dominates the water uptake of WSM extracts in the $\mathrm{RH}$ range above deliquescence with a contribution of about $w_{\text {Inorg }} \approx 59-80 \%$ of total measured particulate water at $90 \% \mathrm{RH}$. Correspondingly, the contribution of the WSOM is about $w_{W S O M} \approx 41-20 \%$ at $90 \%$ RH. Within the WSOM, the contribution of the ISOM is about $w_{I S O M} \approx 6-9 \%$ and 
Relative humidity $R H[\%]$

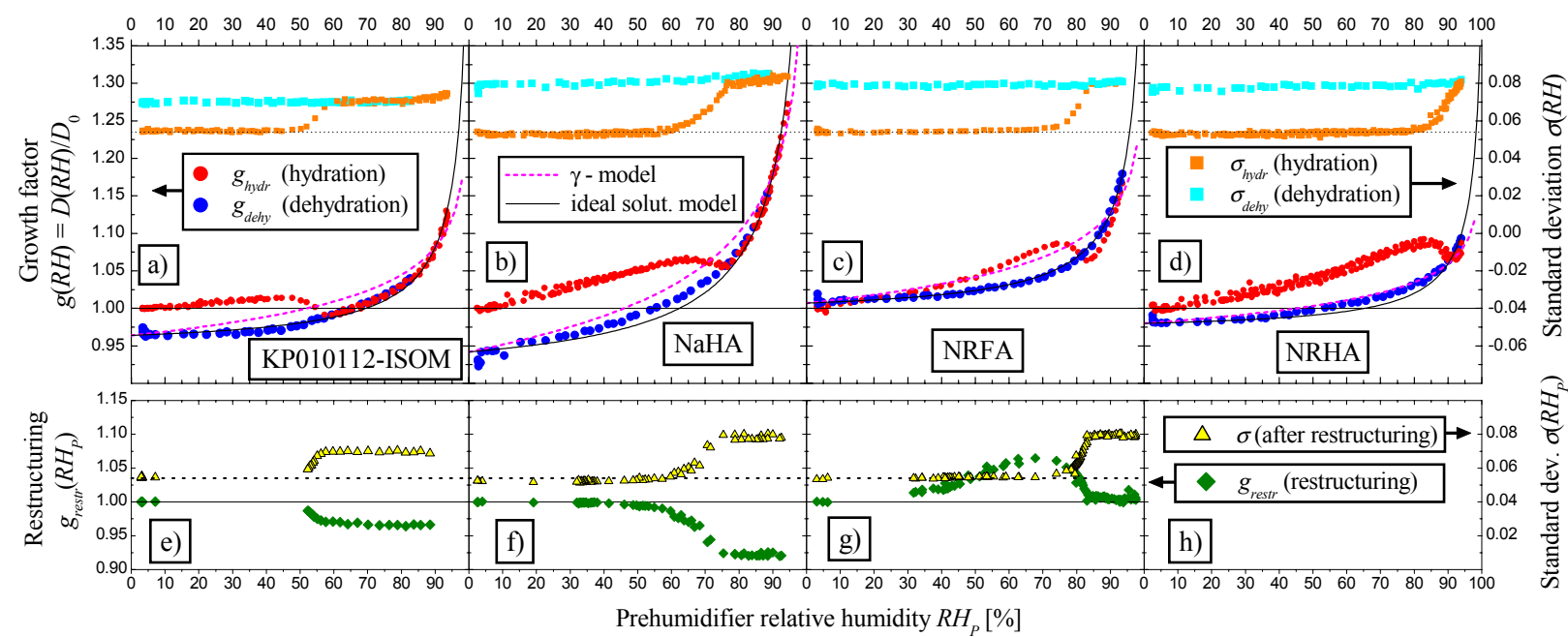

Fig. 7. Hygroscopic properties of particles generated from ISOM, NaHA, NRFA and NRHA solutions: (a)-(d) Hygroscopic growth factors (left ordinate) and broadening (right ordinate) of the monodisperse aerosol as a function of RH (upper abscissa). (e)-(h) Restructuring (left ordinate) and standard deviation (right ordinate) after restructuring as a function of prehumidifier RH (lower abscissa).

the contribution of the MHOM is about $w_{\text {MHOM }} \approx 14-32 \%$. The partitioning of particulate water between different WSM fractions is quite constant in the range $75 \%<\mathrm{RH}<95 \%$.

Despite a comprehensive characterisation of the K-puszta aerosol, the estimated contribution of the MHOM fraction to the water uptake is still quite uncertain regarding all the model assumptions. Nevertheless the experimental and modelling results show that the hygroscopic growth characteristic of WSM is dominated by the inorganic fraction, but that a considerable amount of water is associated with WSOM, whereas contributions from the ISOM and MHOM fractions are probably of comparable relevance. At this point it has to be emphasized that the results of this study are representative of the average WSM composition of the fine aerosol mode $\mathrm{PM}_{1.5}$, and that hygroscopic growth factors of WSM extracts are presumably slightly larger than growth factors of the original ambient aerosol particles since the ambient particles additionally contain a small fraction of WINSOM and BC. However, additional water-insoluble compounds in the particles do not affect percentages of water uptake associated with different WSM fractions, and growth factors of ambient particles could be deduced analogously to the mixed particle model (Eq. 7) by using $g_{W I N S O M+B C}=1$.

Excess water $w_{W S O M}$ amounts obtained in this study for the continental-rural K-puszta aerosol are within the range of results of earlier studies on ambient particles using an $\mathrm{H}$ TDMA (Saxena et al., 1995; Swietlicki et al., 1999; Dick et al., 2000) or a humidity controlled beta gauge (Speer et al., 2003) combined with chemical analysis. Saxena et al. (1995) attributed about $w_{W S O M} \approx 25-40 \%$ of excess water at $80-88 \% \mathrm{RH}$ to the organic fraction of non-urban aerosol in the Grand Canyon. At an urban site in Los Angeles, particulate water was in contrast reduced by the presence of or- ganic substances, i.e. the effective water content was about 25-35\% smaller at $83-93 \% \mathrm{RH}$ than predicted from the inorganic fraction (Saxena et al., 1995). Excess water amounts of about $w_{W S O M} \approx 0,20,44,69 \%$ were observed by Dick et al. (2000) for rural aerosol in the Smoky Mountains with organic mass fractions of about $32,40,58,73 \%$, respectively. In another study, Speer et al. (2003) estimated on average about $w_{W S O M} \approx 20 \%$ to be associated with the organic fraction of a semi-rural aerosol. The hygroscopic growth of aged continental aerosol investigated at Great Dun Fell in northern England by Swietlicki et al. (1999) was explained by the water uptake of the inorganic fraction only, as long as there was only little or no photochemical activity. But they also detected excess water, probably associated with organic compounds, during a period with intense photochemical activity.

Besides particulate water associated with WSOM, another important topic of current research is the possible effect of WSOM on the deliquescence and efflorescence behaviour of inorganic salts (Cruz and Pandis, 2000; Choi and Chan, 2002a; Choi and Chan, 2002b; Hämeri et al., 2002). The AIM2-III model is not generally intended to be applied to calculating the properties of metastable (supersaturated) solutions, though this option is available. Nevertheless, approximate growth curves for dehydration were calculated with the complete mixed particle model in order to obtain more information about the deliquescence behaviour of WSM extracts (see curve "Inorganic+ISOM+MHOM (dehydration)" in Figs. 5 and 6). The comparison of experimental results with modelled growth curves for hydration and dehydration indicates that WSM extracts are fully deliquescent at around $\mathrm{RH}>75-80 \%$. The gradual deliquescence during hydration is fairly well reproduced by the model, but the formation of hydrates (and also of letovicite in case of the KP010726- 
WSM extract) had to be suppressed in AIM2-III. However, it is not possible to decide which salt species were really present, but it can still be concluded that the large organic fraction contained in the WSM extract did not completely suppress the crystallisation of some inorganic salts under the very dry conditions in the diffusion dryer $(\mathrm{RH}<5 \%$ for $\sim 300$ s), nor was the deliquescence behaviour of the solid inorganic salts dramatically changed. This is in agreement with results obtained by Chan and Chan (2003) for mixtures of $\mathrm{NaCl}$ and $\left(\mathrm{NH}_{4}\right)_{2} \mathrm{SO}_{4}$ with humic substances. These findings for deliquescence and efflorescence behaviour are valid for the WSM particles which represent the mean composition of water-soluble matter in fine $\left(\mathrm{PM}_{1.5}\right)$ aerosol at $\mathrm{K}$-puszta. The original ambient aerosol might have been externally mixed containing particles with varying organic/inorganic composition, and hence also varying hygroscopic behaviour.

\subsection{Hygroscopicity of humic reference substances}

Since ISOM has been characterised by different analytical techniques as primarily being composed of humic-like substances, hygroscopic properties of humic reference substances were also investigated. Growth factors (left ordinate) as a function of RH (upper abscissa) are shown in Fig. 7ad for KP010112-ISOM, NaHA, NRFA, and NRHA, respectively. Growth factors at $90 \% \mathrm{RH}$ of NaHA, NRFA, and NRHA are 1.18, 1.13, and 1.06, respectively, which is in the same range as atmospheric ISOM samples. All three reference samples showed hysteresis behaviour basically similar to KP010112-ISOM and KP010726-ISOM (Figs. 7a and 8, detailed discussion below). These results show that there are qualitative similarities between the hygroscopic behaviour of ISOM and humic reference substances, but the deliquescence transition of the reference substances is at higher RH, indicating a lower solubility. The growth factors and deliquescence RHs of NRHA and NRFA could even be somewhat biased towards larger growth factors and lower RH, respectively, if residuals filtered after initial sample dissolution (see above) consisted mainly of the least soluble and possibly least hygroscopic molecules.

\subsection{Deliquescence and hysteresis of organic samples}

A closer analysis of ISOM growth characteristics highlights some uncommon hysteresis features. Figure 8 shows hygroscopic growth factors (left ordinate) of the KP010726-ISOM extract on an enlarged growth scale. During hydration (cf. curve " $g_{h y d r}$ ") the particle size increases continuously from $\mathrm{RH}<5 \%$ to $\mathrm{RH}=30 \%$, followed by a decrease of the particle diameter between 30 and $45 \% \mathrm{RH}$. Above $45 \%$ there is again distinct particle growth up to $95 \%$ RH. Experimental growth factors during dehydration (cf. curve " $g_{\text {dehy }}$ ") are equal to $g_{\text {hydr }}$ between 95 and $45 \%$ RH. Below $45 \%$ evaporation continues during dehydration, ending with a particle size that is smaller than initially selected. However, at the very lower

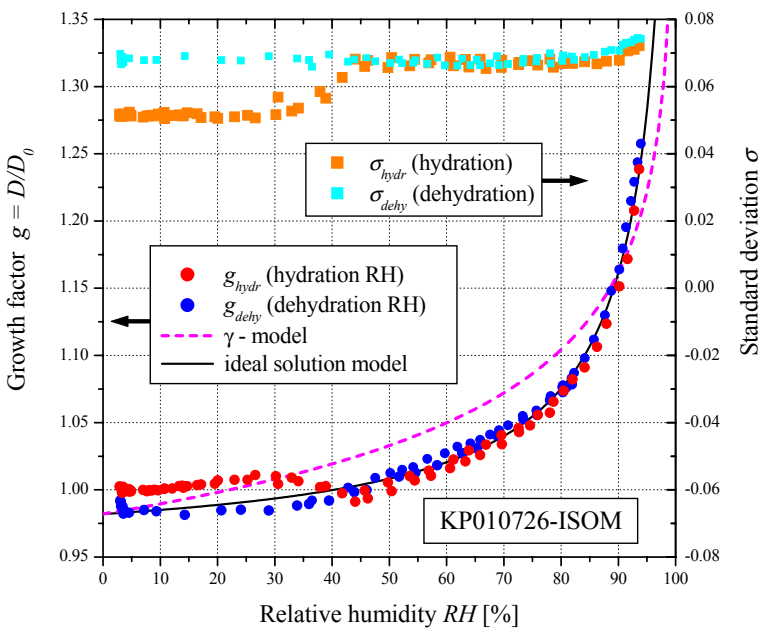

Fig. 8. Hygroscopic growth factors (left ordinate) and corresponding standard deviations (right ordinate) of the KP010726-ISOM sample during hydration and dehydration.

end of the $g_{\text {dehy }}$ measurement $(\mathrm{RH}<5 \%)$ the particle size increases again towards the initially selected diameter. This indicates that crystallisation occurs under these very low RH conditions. The uncommon hysteresis behaviour, i.e. the size reduction at intermediate $\mathrm{RH}$, was detected for all ISOM extracts and for the humic substances (cf. Fig. 7a-d), and it was highly reproducible. Concluding from the continuous evaporation during dehydration, particles are most probably liquid solution droplets once they were exposed to high $\mathrm{RH}$, which may also exist at low RH as metastable supersaturated solutions. Accordingly, the transition during hydration identified by the size reduction and the broadening of $\sigma$, corresponds to deliquescence, i.e. the dissolution of the solid particles.

Each growth factor measured with a H-TDMA is an average value of all particles of the monodisperse aerosol fraction, since it is determined from modal diameters under dry and humid conditions. In parallel, the trend of the modal standard deviation, $\sigma$ (normal distribution), during hygroscopic growth indicates the mixing state of the aerosol. $\sigma$ remains constant (increases) during hygroscopic growth, if growth factors of individual particles are equal (different). Figure 9 illustrates the changes of the monodisperse size distribution at different RH for NaHA (cf. corresponding $g$ and $\sigma$ values in Fig. 7b). The line "RH $=2 \%$ " corresponds to the initially selected monodisperse aerosol fraction $\left(D_{0}=104 \mathrm{~nm}\right)$. During hydration the particles grow homogeneously to a mean diameter of $D=110 \mathrm{~nm}$ at $51 \% \mathrm{RH}$, i.e. there is no change of the standard deviation $\sigma$. From 51 to $79 \% \mathrm{RH}$ the mean particle size increases only slightly to $D=112 \mathrm{~nm}$, but there is a distinct broadening of the monodisperse size distribution. Between 79 and $89 \%$ RH there is again homogeneous growth up to a diameter of $D=121 \mathrm{~nm}$. During dehydration the modal diameter decreases continuously without any further change of the size distribution 


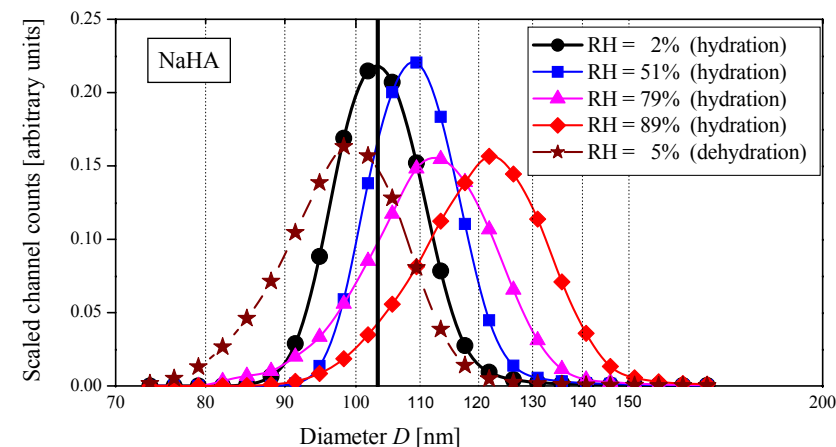

Fig. 9. Size changes and broadening of the monodisperse NaHAaerosol at different RH. Initial dry size $\left(D_{0}=103 \mathrm{~nm}\right)$ marked with a vertical line.

shape, ending with a diameter of $D=99 \mathrm{~nm}$ at $5 \% \mathrm{RH}$ (line "RH=5\% (dehydration)"). Thus the hygroscopic growth of NaHA particles is always homogeneous, except for the deliquescence transition between 60 and $75 \% \mathrm{RH}$, where there is a broadening of the monodisperse aerosol. ISOM (cf. Figs. 7a and 8) as well as NRFA (Fig. 7c) and NRHA (Fig. 7d) exhibit this characteristic decrease of the electrical mobility diameter accompanied by a parallel increase of $\sigma$ during deliquescence, too.

A priori one would expect no broadening of the monodisperse aerosol fraction during growth for these internally mixed aerosols composed of particles with identical composition (see above). But how can the broadening during deliquescence be explained? There are mainly two possible reasons (cf. also Sect. 3.4) explaining a mobility diameter decrease during deliquescence despite the parallel water uptake: a) the dynamic shape factor of the solid particles is larger than 1 , i.e. they are not perfectly spherical and they have cracks or cavities, leading to a decrease of the electrical mobility diameter only when the particles are transformed into compact spheres during dissolution b) the volume of mixing of humic-like substances with water is negative causing a real size decrease in terms of electrical mobility and volume equivalent diameters. Variations of the solid particle density and of the initial dynamic shape factor between individual particles then lead to the observed broadening of the monodisperse aerosol fraction during deliquescence despite identical chemical composition. However, at this point it has to be mentioned, that the hysteresis of all humic-like substances is small compared to the hysteresis of inorganic salts (e.g. $\left.\left(\mathrm{NH}_{4}\right)_{2} \mathrm{SO}_{4}\right)$, and could only be detected due to the high instrument resolution (cf. KP010726-ISOM in Fig. 8). This uncommon decrease in mobility diameter at deliquescence is most probably not of atmospheric importance, but it should be kept in mind as a potential source of discrepancies between results obtained with different techniques, e.g. if mobility diameter growth factors are compared with mass gains.
The relatively small growth below deliquescence is attributed to a surface effect, where the most soluble compounds might form a liquid solution shell. Water adsorption alone is not sufficient to explain this growth, since a growth factor of 1.05 (e.g. NRFA at 52\% RH, Fig. 7c) corresponds to an equivalent of $\sim 6$ monolayers of water.

For all WSM samples a small size decrease in parallel with a broadening of the monodisperse aerosol was also observed during hydration somewhere between 10 and $40 \%$ RH (cf. Figs. 4-6). This is attributed to a microstructural rearrangement (see above) which might be induced at these low RH conditions by a partial dissolution of WSOM and possibly also some inorganic salts.

\subsection{Restructuring}

The restructuring $g_{\text {restr }}\left(\mathrm{RH}_{P}\right)$ of ISOM, NaHA, and NRFA particles as a function of prehumidifier $\mathrm{RH}\left(\mathrm{RH}_{P}\right)$ was also measured (Figs. 7e-g). In this instrument mode (cf. Fig. 3d) particles are selected under dry conditions in DMA1, exposed to a certain $\mathrm{RH}_{P}$, dried again in the $\mathrm{RH}$-conditioner and the restructured dry size is measured in DMA2. No restructuring or broadening below deliquescence RH was detected for ISOM and NaHA, i.e. the hygroscopic growth during hydration in the range $\mathrm{RH}<\mathrm{DRH}$ is reversible. Through the deliquescence transition there is continuous restructuring (decrease of $g_{\text {restr }}$ ) accompanied by a broadening of the standard deviation. This indicates that the reduction of the electrical mobility diameter during dissolution is irreversible on this timescale ( $\sim 5 \mathrm{~s}$ residence time after the RHconditioner), which is in agreement with the observation of supersaturated solutions and growth factors $g_{d e h y}<1$ at low $\mathrm{RH}$ during dehydration. There is no further restructuring or broadening above the deliquescence transition, confirming that in this RH range, size changes during hydration or dehydration are only a result of water condensation or evaporation. While the restructuring behaviour of NRFA is similar to ISOM and NaHA during deliquescence and at higher RH, it is different below deliquescence. Restructuring factors $g_{\text {restr }}$ larger than 1 in the RH range below deliquescence indicate that the hygroscopic growth of NRFA is to some extent irreversible on this time scale, i.e. the NRFA particles keep some water at low $\mathrm{RH}$.

\subsection{Empirical $\gamma$-model and ideal solution model}

Empirical growth curves ( $\gamma$-model) were fitted to experimental growth factors at $90 \%$ RH of WSM, ISOM and humic reference substances (see Figs. 4, 7, and 8). The empirical $\gamma$-model is not able of reproducing the observed hygroscopic growth factors very precisely. Nevertheless, the relative agreement between fitted and measured growth factors during dehydration is better than $\pm 6 \%$ in the range from 60 to $90 \% \mathrm{RH}$ for all WSM samples, and better than $\pm 4 \%$ and $\pm 3 \%$ in the entire $\mathrm{RH}$ range for all ISOM samples and humic 
reference substances, respectively. The $\gamma$-model is hence a simple but useful tool to describe the hygroscopic growth of WSM, ISOM, and humic reference substances.

The ideal solution model was applied to describe the hygroscopic growth of ISOM and humic reference substances, where $v_{s}$ was used to fit theoretical growth curves to experimental results (cf. Eq. 4). It reproduces the experimental growth characteristic of ISOM and humic reference substances much better compared to the empirical $\gamma$-model (see Figs. 4, 7, and 8). The relative agreement between measured and modelled growth factors in the entire $\mathrm{RH}$ range is better than $\pm 1 \%$ and $\pm 2 \%$ for all ISOM samples and humic reference substances, respectively. This does not essentially mean that the solution behaviour is in reality ideal, but this model is at least suitable to describe the hygroscopic behaviour and to get a rough estimate of the effective molar mass $M_{I S O M}$ of the ISOM, according to the approach described in Sect. 3.1. For the latter purpose $\rho_{I S O M}$ and the van't Hoff factor $i_{\text {ISOM }}$ were assumed to be $1500 \mathrm{~kg} / \mathrm{m}^{3}$ (cf. above) and 1, respectively. The van't Hoff factor of acidic compounds is in principle always $>1$, but since the $\mathrm{pK}_{a}$ of ISOM ranges from 3 to $9, i_{I S O M}$ is in fact expected to be smaller than 1.03 for a solution droplet at $\mathrm{RH} \leq 95 \%$ (conc. $\geq 1.8 \mathrm{M}$ ). MISOM values obtained with the ideal solution model under the above-mentioned assumptions are between 300 and $495 \mathrm{~kg} / \mathrm{kmol}$ (see Table 2). $M_{I S O M}$ estimates are proportional to $\rho_{I S O M}$ and $i_{I S O M}$ for a given $v_{S}$ (see Eq. 5), i.e. assuming a lower ISOM density of $\rho_{I S O M}=1000 \mathrm{~kg} / \mathrm{m}^{3}$, results in $M_{I S O M}$ estimates between 200 and $330 \mathrm{~kg} / \mathrm{kmol}$. As discussed in Sect. 3.1, solution surface tension $\varsigma$ was approximated by the surface tension of pure water. However, measurements of the influence of other ISOM samples on the surface tension of water and $\left(\mathrm{NH}_{4}\right)_{2} \mathrm{SO}_{4}$-solution (Kiss et al., 2004) samples showed that ISOM reduces the surface tension typically by about $40 \%$ at a moderate concentration of $1 \mathrm{~g} / \mathrm{l}$. On the other hand, $M_{I S O M}$ estimates increase only about $10 \%$ if one assumes a $50 \%$ reduction of surface tension by ISOM. Kiss et al. (2003) determined the average molar mass of ISOM extracted from filters sampled at K-puszta between March 1999 and June 2000. They reported values of 200-300 and 215-345 kg/kmol using liquid chromatography mass spectrometry and vapour pressure osmometry, respectively. This is good agreement between these three approaches regarding the fact that molar mass estimates of humic substances often vary more than an order of magnitude depending on the applied experimental technique.

Molar mass estimates, also assuming a density of $\rho_{\text {humic }}=1500 \mathrm{~kg} / \mathrm{m}^{3}$ and a van't Hoff factor of $i_{\text {humic }}=1$, for NaHA, NRFA, and NRHA are 216, 510, and $765 \mathrm{~kg} / \mathrm{kmol}$, respectively. $M_{w}$ estimates for the NRFA and NRHA samples are thus larger than estimates for ISOM. This is in agreement with the stronger refractory character of NRFA and NRHA during volatilisation compared to ISOM (Nyeki et al., 2003). Distinctly larger molar masses (number averaged) of $2180 \mathrm{~kg} / \mathrm{kmol}$ and $4410 \mathrm{~kg} / \mathrm{kmol}$ for NRFA and NRHA, respectively, have previously been reported by Pettersson et al. (1994). However, they used size exclusion chromatography which has been reported to give higher average molar mass estimates for humic substances than other techniques (Leenheer et al., 2001).

Recently, the osmotic coefficient parameterisation for globular macromolecules has been derived and applied to the hygroscopic growth of macromolecular substances (Mikhailov et al., 2003). This model was also tested to fit the hygroscopic growth of ISOM, NRFA and NRHA particles investigated in this study, whereas the molar mass was used as a fit parameter, similarly to the ideal solution model. Growth curves obtained with this model did not match experimentally observed growth curves over the whole $\mathrm{RH}$ range. Resulting effective molar mass estimates depend hence considerably on the RH range chosen for fitting. Effective molar mass estimates are about a factor of 1.5 higher for ISOM and nearly an order of magnitude higher for NRHA compared to estimates from the ideal solution model. These findings indicate that effective molar mass estimates obtained with the ideal solution model are possibly biased towards low values, whereas this effect becomes more important for large molecules, in particular for NRHA.

A value of $M_{N a H A} \approx 3300 \mathrm{~kg} / \mathrm{kmol}$ (average by weight) was reported by Wolf et al. (2001) for NaHA. The effective molar mass estimate of $216 \mathrm{~kg} / \mathrm{kmol}$, obtained in this study for NaHA, is most probably too low, since the sodium ions are expected to dissociate, and the van't Hoff factor is hence $>1$. If one considers a sodium mass fraction of $\sim 9 \mathrm{wt} \%$ (Aldrich product analysis) and assumes that all sodium ions dissociate, one would end up with a van't Hoff factor of $i_{N a H A} \approx 6.5$ and an effective molar mass (before dissociation) of $M_{N a H A} \approx 1400 \mathrm{~kg} / \mathrm{kmol}$, but also these corrected values are not reliable since the deduction is highly sensitive to small uncertainties of the initial value.

\section{Conclusions}

Ambient continental-rural fine aerosol was sampled on quartz filters and WSM was extracted in MilliQ-water. Solid phase extraction was subsequently used to isolate ISOM, constituting the major (less hydrophilic) fraction of WSOM, from inorganic salts and the remaining MHOM. Extensive chemical characterisation of these extracts was carried out by Galambos et al. (2004), while hygroscopic properties were investigated here using a H-TDMA instrument. ISOM hygroscopicity was comparable to secondary organic aerosols, which were obtained in smog chamber studies by oxidation of typical gaseous precursors, but lower than the hygroscopicity of highly soluble organic acids. Deliquescence was already observed at moderate RH between 30 and $60 \%$ for different ISOM samples. Differences between summer and winter samples were small, but there is a trend towards slightly larger hygroscopicity and lower deliquescence $\mathrm{RH}$ in 
summer. Köhler theory for ideal solutions was used to estimate the effective molar mass of ISOM. Resulting $M_{I S O M}$ estimates of $300-495 \mathrm{~kg} / \mathrm{kmol}$ assuming a van't Hoff factor of $i_{I S O M}=1$ and a density of $\rho_{I S O M}=1500 \mathrm{~kg} / \mathrm{m}^{3}$ are in good agreement with earlier investigations of K-puszta ISOM using liquid chromatography mass spectrometry and vapour pressure osmometry. However, model calculations using the osmotic coefficient parameterisation for globular macromolecules indicated that these values obtained with the ideal solution model are possibly biased to low values. Aquatic fulvic and humic acids were also investigated for comparison with ISOM. Although some similarities in hygroscopic behaviour were observed, fulvic and humic acids were slightly less hygroscopic and deliquescence occurred at higher $\mathrm{RH}$ compared to ISOM. This indicates a lower molar mass and higher solubility of ISOM. Deliquescence of ISOM, fulvic acid, and humic acid was characterised by a small but nevertheless uncommon decrease in mobility diameter. This behaviour is probably not of atmospheric importance, but it is a potential source of discrepancy between different techniques to measure hygroscopic growth of particles.

Comprehensive chemical information and measured hygroscopic properties of ISOM were used to model the hygroscopic growth of the WSM. Good agreement between model predictions and measurements was obtained. The analysis of modelled and measured WSM growth factors showed furthermore that between 20 and $40 \%$ of total particulate water is associated with WSOM. This finding confirms results from earlier studies that, apart from inorganic salts, organic compounds are also actively involved in atmospheric processes in which particle hygroscopic properties are crucial. The relative contributions of the distinct WSOM fractions, ISOM (67-71 wt \%) and MHOM (33-29wt \%), remains uncertain since MHOM was not available in isolated form, but the results suggest that the less abundant MHOM was also important due to its presumably larger hygroscopicity.

\section{Glossary}

Abbreviations were generally adopted from literature. However, an "M" (matter) instead of a "C" (carbon) as the last letter (e.g. WSOM instead of WSOC) is used to clearly distinguish between the mass of carbonaceous compounds and their carbon mass content.

\subsection{Acronyms}

$\begin{array}{ll}\text { AIM } & \text { aerosol inorganic model } \\ \text { BC } & \text { black carbon } \\ \text { CPC } & \text { condensation particle counter } \\ \text { DMA } & \text { differential mobility analyser } \\ \text { DRH } & \text { deliquescence relative humidity } \\ \text { H-TDMA } & \text { hygroscopicity tandem differential } \\ & \text { mobility analyser }\end{array}$

$\begin{array}{ll}\text { ISOM } & \begin{array}{l}\text { isolated organic matter } \\ \text { KPyymmdd }\end{array} \\ & \begin{array}{l}\text { K-puszta and the sampling date } \\ \text { most hydrophilic organic matter }\end{array} \\ \text { MHOM } & \text { Aldrich humic acid sodium salt } \\ \text { NaHA } & \text { nordic reference fulvic acid } \\ \text { NRFA } & \text { nordic reference humic acid } \\ \text { NRHA } & \text { particulate matter with diameter } \leq 1.5 \mu \mathrm{m} \\ \text { PM }_{1.5} & \text { scanning electron microscopy } \\ \text { SEM } & \text { total carbonaceous matter } \\ \text { TCM } & \text { water-insoluble organic matter } \\ \text { WINSOM } & \text { water-soluble matter } \\ \text { WSM } & \text { water-soluble organic matter } \\ \text { WSOM } & \text { Zdanovskii-Stokes-Robinson relation }\end{array}$

\subsection{Symbols}

$\begin{array}{ll}D & \text { particle diameter } \\ D_{0} & \text { dry reference diameter } \\ f & \text { mobility correction factor } \\ g & \text { hygroscopic growth factor }\left(D / D_{0}\right) \\ g_{\text {dehy }} & \text { hygroscopic growth factor during dehydration } \\ g_{\text {hydr }} & \text { hygroscopic growth factor during hydration } \\ g_{\text {restr }} & \text { restructuring factor } \\ g_{t h} & \text { theoretical hygroscopic growth factor } \\ i_{s} & \text { van't Hoff factor of the solute } \\ M_{w} & \text { molar mass of water } \\ M_{S} & \text { molar mass of the solute } \\ n_{w} & \text { molar number of water molecules } \\ n_{S} & \text { molar number of solute molecules (or ions) } \\ R & \text { ideal gas constant } \\ \mathrm{RH}_{C} & \text { relative humidity in the RH-conditioner } \\ \mathrm{RH}_{D M A 2} & \text { relative humidity in the second DMA } \\ \mathrm{RH}_{P} & \text { relative humidity in the prehumidifier } \\ S_{K e l v i n} & \text { Kelvin correction factor } \\ T & \text { temperature } \\ x_{w} & \text { mole fraction of water } \\ \gamma & \text { model parameter of the } \gamma \text {-model } \\ \varepsilon & \text { volume fraction } \\ v_{s} & \text { effective molar volume of solute molecules } \\ \rho & \text { mass density } \\ \rho_{w} & \text { density of water } \\ 5 & \text { surface tension } \\ \sigma & \text { standard deviation (normal distribution) of } \\ & \text { the monodisperse aerosol } \\ & \end{array}$

Acknowledgements. We thank R. Brütsch for providing SEM micrographs. This work was conducted with financial support from the Swiss Bundesamt für Bildung und Wissenschaft, the Swiss National Science Foundation, and the European Commission (PartEmis project, No. 99.0632 and G4RD-CT-2000-00207, respectively). Supports from the Hungarian Scientific Research Fund (OTKA 029610), the János Bolyai Research Fellowship of the Hungarian Academy of Sciences, and the Peregrinatio I. Fund are also gratefully acknowledged. 


\section{References}

Ansari, A. S. and Pandis, S. N.: Prediction of multicomponent inorganic atmospheric aerosol behavior, Atmos. Env., 33, 745-757, 1999.

Chan, M. N. and Chan, C. K.: Hygroscopic properties of two model humic-like substances and their mixtures with inorganics of atmospheric importance, Environ. Sci. Technol., 37, 5109-5115, 2003.

Chen, H., Sangster, J., Teng, T. T., and Lenzi, F.: General method of predicting water activity of ternary aqueous-solutions from binary data, Can. J. Chem. Eng., 51, 234-241, 1973.

Choi, M. Y. and Chan, C. K.: The effects of organic species on the hygroscopic behaviors of inorganic aerosols, Environ. Sci. Technol., 36, 2422-2428, 2002a.

Choi, M. Y. and Chan, C. K.: Continuous measurements of the water activities of aqueous droplets of water-soluble organic compounds, J. Phys. Chem. A, 106, 4566-4572, 2002 b.

Clegg, S. L., Brimblecombe, P., and Wexler, A. S.: Thermodynamic model of the system $\mathrm{H}^{+}-\mathrm{NH}_{4}^{+}-\mathrm{Na}^{+}-\mathrm{SO}_{4}^{2-}-\mathrm{NO}_{3}^{-}-\mathrm{Cl}^{-}-\mathrm{H}_{2} \mathrm{O}$ at 298.15 K, J. Phys. Chem. A, 102, 2155-2171, 1998.

Clegg, S. L., Seinfeld, J. H., and Brimblecombe, P.: Thermodynamic modelling of aqueous aerosols containing electrolytes and dissolved organic compounds, J. Aerosol Sci., 32, 713-738, 2001.

Cocker III, D. R., Clegg, S. L., Flagan, R. C., and Seinfeld, J. H.: The effect of water on gas-particle partitioning of secondary organic aerosol. Part I: $\alpha$-pinene/ozone system, Atmos. Env., 35, 6049-6072, 2001a.

Cocker III, D. R., Mader, B. T., Kalberer, M., Flagan, R. C., and Seinfeld, J. H.: The effect of water on gas-particle partitioning of secondary organic aerosol: II. m-xylene and 1,3,5trimethylbenzene photooxidation systems, Atmos. Env., 35, 6073-6085, 2001b.

Corrigan, C. E. and Novakov, T.: Cloud condensation nucleus activity of organic compounds: a laboratory study, Atmos. Env., 33, 2661-2668, 1999.

Cruz, C. N. and Pandis, S. N.: A study of the ability of pure secondary organic aerosol to act as cloud condensation nuclei, Atmos. Env., 31, 2205-2214, 1997.

Cruz, C. N. and Pandis, S. N.: The effect of organic coatings on the cloud condensation nuclei activation of inorganic atmospheric aerosol, J. Geophys. Res., 103D, 13 111-13 123, 1998.

Cruz, C. N. and Pandis, S. N.: Deliquescence and hygroscopic growth of mixed inorganic-organic atmospheric aerosol, Environ. Sci. Technol., 34, 4313-4319, 2000.

Dick, W. D., Saxena, P., and McMurry, P. H.: Estimation of water uptake by organic compounds in submicron aerosols measured during the Southeastern Aerosol and Visibility Study, J. Geophys. Res., 105D, 1471-1479, 2000.

Facchini, M. C., Fuzzi, S., Zappoli, S., Andracchio, A., Gelencsér, A., Kiss, G., Krivácsy, Z., Mészáros, E., Hansson, H. C., Alsberg, T., and Zebühr, Y.: Partitioning of the organic aerosol component between fog droplets and interstitial air, J. Geophys. Res., 104D, 26 821-26 832, 1999.

Galambos, I., Kiss, G., Horváth, E., Molnár, Á., Gysel, M., Nyeki, S., Weingartner, E., and Baltensperger, U.: Chemical characterisation of water-soluble matter and humic-like organics in atmospheric fine aerosol, manuscript in preparation, 2004.
Giebl, H., Berner, A., Reischl, G., Puxbaum, H., Kasper-Giebl, A., and Hitzenberger, R.: CCN activation of oxalic and malonic acid test aerosols with the University of Vienna cloud condensation nuclei counter, J. Aerosol Sci., 33, 1623-1634, 2002.

Gysel, M., Weingartner, E., and Baltensperger, U.: Hygroscopicity of aerosol particles at low temperatures, 2 . Theoretical and experimental hygroscopic properties of laboratory generated aerosols, Environ. Sci. Technol., 36, 63-68, 2002.

Hämeri, K., Laaksonen, A., Väkevä, M., and Suni, T.: Hygroscopic growth of ultrafine sodium chloride particles. J. Geophys. Res., 106, 20 749-20 757, 2001.

Hämeri, K., Charlson, R., and Hansson, H. C.: Hygroscopic properties of mixed ammonium sulfate and carboxylic acids particles, AICHE J., 48, 1309-1316, 2002.

Hansson, H.-C., Rood, M. J., S., K.-V., Hämeri, K., Orsini, D., and Wiedensohler, A.: $\mathrm{NaCl}$ aerosol particle hygroscopicity dependence on mixing with organic compounds, J. Atmos. Chem., 31, 321-346, 1998.

Heintzenberg, J.: Fine particles in the global troposphere, A review, Tellus, 41B, 149-160, 1989.

Kiss, G., Varga, B., Galambos, I., and Ganszky, I.: Characterization of water-soluble organic matter isolated from atmospheric fine aerosol, J. Geophys. Res., 107D, 8339, doi:10.1029/2001JD000603, 2002.

Kiss, G., Tombácz, E., Varga, B., Alsberg, T., and Persson, L.: Estimation of the average molecular weigth of humic-like substances isolated from fine atmospheric aerosol, Atmos. Env., 37, 3783 3794, 2003.

Kiss, G., Tombácz, E., Gelencsér, A., Krivácsy, Z., Molnár, Á., Mészáros, E., and Hansson, H.-C.: Surface tension effects of water-soluble organic matter in nucleating cloud droplets, manuscript in preparation, 2004.

Krämer, L., Pöschl, U., and Niessner, R.: Microstructural rearrangement of sodium chloride condenstaiton aerosol particles on interaction with water vapour. J. Aerosol Sci., 31, 673-685, 2000.

Krivácsy, Z., Gelencsér, A., Kiss, G., Mészáros, E., Molnár, Á., Hoffer, A., Mészáros, T., Sárvári, Z., Temesi, D., Varga, B., Baltensperger, U., Nyeki, S., and Weingartner, E.: Study on the chemical character of water soluble organic compounds in fine atmospheric aerosol at the Jungfraujoch, J. Atmos. Chem., 39, 235-259, 2001.

Leenheer, J. A., Rostad, C. E., Gates, P. M., Furlong, E. T., and Ferrer, I.: Molecular resolution and fragmentation of fulvic acid by electrospray ionization/multistage tandem mass spectrometry, Anal. Chem., 73, 1461-1471, 2001.

Lightstone, J. M., Onasch, T. B., Imre, D., and Oatis, S.: Deliquescence, efflorescence, and water activity in ammonium nitrate and mixed ammonium nitrate/succinic acid microparticles, J. Phys. Chem. A, 104, 9337-9346, 2000.

Massling, A., Wiedensohler, A., Busch, B., Neusüss, C., Quinn, P., Bates, T., and Covert, D.: Hygroscopic properties of different aerosol types over the Atlantic and Indian Oceans, Atmos. Chem. Phys., 3, 1377-1397, 2003.

Mikhailov, E., Vlasenko, S., Niessner, R., and Pöschl, U.: Interaction of aerosol particles composed of protein and salts with water vapor: hygroscopic growth and microstructural rearrangement. Atmos. Chem. Phys. Discuss., 3, 4755-4832, 2003.

Ming, Y. and Russell, L. M.: Predicted hygroscopic growth of sea salt aerosol. J. Geophys. Res., 106D, 28 259-28 274, 2001. 
Ming, Y. and Russell, L. M.: Thermodynamic equilibrium of organic-electrolyte mixtures in aerosol particles, AICHE J., 48, 1331-1348, 2002.

Na, H. S., Arnold, S., and Myerson, A. S.: Water activity in supersaturated aqueous-solutions of organic solutes, J. Cryst. Growth, 149, 229-235, 1995.

Nyeki, S., Baltensperger, U., Coulson, G., Galambos, I., Gysel, M., Kiss, G., Krivácsy, Z., and Colbeck, I.: Properties of humic-like organics isolated from atmospheric fine aerosol. Aerosol volatility. Proc. European Aerosol Conference 2003, Madrid, 31 Aug.05 Sept. 2003, J. Aerosol Sci., S225-S226, 2003.

Peng, C., Chan, M. N., and Chan, C. K.: The hygroscopic properties of dicarboxylic and multifunctional acids: Measurements and UNIFAC predictions, Environ. Sci. Technol., 35, 4495-4501, 2001.

Peng, C. G. and Chan, C. K.: The water cycles of water-soluble organic salts of atmospheric importance, Atmos. Env., 35, 11831192, 2001.

Pettersson, C., Ephraim, J., and Allard, B.: On the composition and properties of humic substances isolated from deep groundwater and surface waters, Org. Geochem., 21, 443-451, 1994.

Prenni, A. J., DeMott, P. J., Kreidenweis, S. M., Sherman, D. E., Russell, L. M., and Ming, Y.: The effects of low molecular weight dicarboxylic acids on cloud formation, J. Phys. Chem. A, 105, $11240-11248,2001$.

Pruppacher, H. R. and Klett, J. D.: Microphysics of Clouds and Precipitation, Kluwer Academic Publishers, Dordrecht, 1997.

Rader, D. J. and McMurry, P. H.: Application of the tandem differential mobility analyzer to studies of droplet growth or evaporation, J. Aerosol Sci., 17, 771-787, 1986.

Saathoff, H., Naumann, K.-H., Schnaiter, M., Schöck, W., Möhler, O., Schurath, U., Weingartner, E., Gysel, M., and Baltensperger, U.: Coating of soot and $\left(\mathrm{NH}_{4}\right)_{2} \mathrm{SO}_{4}$ particles by ozonolysis products of $\alpha$-pinene, J. Aerosol Sci., 34, 1297-1321, 2003.

Saxena, P. and Hildemann, L. M.: Water-soluble organics in atmospheric particles: A critical review of the literature and application of thermodynamics to identify candidate compounds, J. Atmos. Chem., 24, 57-109, 1996.

Saxena, P., Hildemann, L. M., McMurry, P. H., and Seinfeld, J. H.: Organics alter hygroscopic behavior of atmospheric particles, J. Geophys. Res., 100D, 18 755-18 770, 1995.
Seinfeld, J. H. and Pandis, S. N.: Atmospheric Chemistry and Physics. From Air Pollution to Climate Change, John Wiley \& Sons, Inc., New York, 1998.

Speer, R. E., Edney, E. O., and Kleindienst, T. E.: Impact of organic compounds on the concentrations of liquid water in ambient $\mathrm{PM}_{2.5}$. J. Aerosol Sci., 34, 63-77, 2003.

Stolzenburg, M. R. and McMurry, P. H.: TDMAFIT user's manual, University of Minnesota, Department of Mechanical Engineering, Particle Technology Laboratory, Minneapolis, 1988.

Swietlicki, E., Zhou, J. C., Berg, O. H., Martinsson, B. G., Frank, G., Cederfelt, S. I., Dusek, U., Berner, A., Birmili, W., Wiedensohler, A., Yuskiewicz, B., and Bower, K. N.: A closure study of sub-micrometer aerosol particle hygroscopic behaviour, Atmos. Res., 50, 205-240, 1999.

Swietlicki, E., Zhou, J. C., Covert, D. S., Hämeri, K., Busch, B., Vakeva, M., Dusek, U., Berg, O. H., Wiedensohler, A., Aalto, P., Makela, J., Martinsson, B. G., Papaspiropoulos, G., Mentes, B., Frank, G., and Stratmann, F.: Hygroscopic properties of aerosol particles in the north-eastern Atlantic during ACE-2, Tellus, 52, 201-227, 2000.

Varga, B., Kiss, G., Ganszky, I., Gelencsér, A., and Krivácsy, Z.: Isolation of water-soluble organic matter from atmospheric aerosol, Talanta, 55, 561-572, 2001.

Virkkula, A., Van Dingenen, R., Raes, F., and Hjorth, J.: Hygroscopic properties of aerosol formed by oxidation of limonene, $\alpha$ pinene, and $\beta$-pinene, J. Geophys. Res., 104D, 3569-3579, 1999.

Weingartner, E., Gysel, M., and Baltensperger, U.: Hygroscopicity of aerosol particles at low temperatures. 1. New low-temperature H-TDMA instrument: Setup and first applications, Environ. Sci. Technol., 36, 55-62, 2002.

Wolf, M., Buckau, G., Geckeis, H., Thang, N. M., Hoque, E., Szymczak, W., and Kim, J.-I.: Aspects of measurement of the hydrodynamic size and molecular mass distribution of humic and fulvic acids, in Humic Substances. Structures, Models and Functions, edited by Ghabbour, E. A., and Davies, G., pp. 51-61, The Royal Society of Chemistry, Cambridge, 2001.

Zappoli, S., Andracchio, A., Fuzzi, S., Facchini, M. C., Gelencsér, A., Kiss, G., Krivácsy, Z., Molnár, á., Mészáros, E., Hansson, H.C., Rosman, K., and Zebühr, Y.: Inorganic, organic and macromolecular components of fine aerosol in different areas of Europe in relation to their water solubility, Atmos. Env., 33, 2733-2743, 1999. 